\title{
Universum of education in the context of the whole and part
}

\author{
Nikolay Rybakov ${ }^{1 *}$ and Natalya Yarmolich $^{1}$ \\ ${ }^{1}$ Pskov State University, 2, Lenin Place, Pskov, 180000, Russia
}

\begin{abstract}
Although at present there are quite a few studies on the philosophy of education, nevertheless, their authors pay insufficient attention to understanding the phenomenon of education as a universal phenomenon of social life. This article analyzes education not only as a socio-cultural phenomenon, but is considered more broadly as an integral (single-separate) system with many components. This allows us to formulate the main question of the philosophy of education, to present education as a universe, closely linking the state, society and person into a single whole. In this regard, the authors intend to show that the solution of the numerous problems facing society in crisis situations depends on the solution of the main issue of the philosophy of education. They proceed from the fact that the essence of education lies in the ascent of man to universal nature, as Hegel spoke about in his time, and the most important component of this process is the awakening of spirituality. The need to bring the real educational process into conformity with its idea (meaning) is revealed as the most important condition and criterion for the effectiveness of education. The idea of education carries the maximum generalized potential of studying the phenomenon of education and shows that education as a whole cannot be reduced or viewed through the prism of any one of its components.
\end{abstract}

\section{Introduction}

At the beginning of the $90 \mathrm{~s}$, an intensive development of a new branch of philosophical knowledge - the philosophy of education - began in Russia. Numerous conferences and congresses were held, many publications, round tables appeared, where the status and subject of a new philosophical discipline were discussed, its prospects were clarified, and its place among other sciences involved in the phenomenon of education. Programs for the development of education in the country and in the regions were developed everywhere. In various universities and administrative structures, departments appeared under the name "philosophy of education". In 1992, at the Pskov Regional Institute for Advanced Training of Teachers (Pskov), one of the first in Russia Department of Philosophy and Sociology of Education was created, the head of which at the beginning of 1993 was elected one of the authors of this article. The creation of such a department within the framework of the

\footnotetext{
* Corresponding author: malkogospel@mail.ru
} 
Institute for Advanced Training of Educators - the Pskov Institute for Advanced Training of Teachers at the same time was renamed - was dictated by the practical need to transform the process of advanced training of teachers.

At this point, we consider it our duty to clarify the facts indicated in the article by O.A. Beregova regarding the fact that in 2008 in Russia the only department of philosophy of education was opened at the Faculty of Philosophy of Moscow State University [1]. The Department of Philosophy and Sociology of Education (renamed in 2004 as the Department of Philosophy of Education) at the Pskov Regional Institute for Advanced Training of Educators was created 16 years earlier than at Moscow State University. Unfortunately, in 2005 , in connection with the reorganization of the structure of the institute, it ceased to exist. Of course, a provincial institution can hardly compare in status with the most famous universities in Russia and the world. Nevertheless, this fact testifies to the fact that intensive searches for solutions to pressing problems of our time are going on not only in the famous centers of science and education.

From the middle of the twentieth century. in the West, the institutionalization of the philosophy of education begins. In the 40s of the XX century. in the United States, the Society for the Philosophy of Education was created; after the Second World War, such a society appeared in European countries. The publication of specialized journals on the philosophy of education began (first also in the USA, then in Europe), as well as monographic studies and collections [2].

Since the 90s, magazines and other works of this type have been published in Russia. In 2004, this philosophical trend was institutionalized: the All-Russian Association of Educational Philosophers was organized, which included representatives of 27 constituent entities of the Russian Federation, including the Department of Philosophy and Sociology of Education at the Pskov Institute.

At present, the philosophy of education is an important and serious direction of philosophical research conducted at the intersection of philosophy, pedagogy, andragogy, psychology, cultural studies, sociology, religious studies, political science, anthropology and other fields of knowledge. As rightly stated in one of the articles: "Modern philosophy of education is an area of interdisciplinary research, the main principle and condition for its construction and development is the interaction of related scientific disciplines" [3]. But this requires clarification and detail. The fact is that inter- and multidisciplinary research has its reverse side blurring the boundaries of the object of research, in this case, education, from which the philosophical interpretation of the educational process loses its conceptuality.

In the mid-90s, on the instructions of the Education Department under the Administration of the Pskov Region, a group of scientists was formed, who were to develop a Program for the Development of Education in the Pskov Region for 1996-2000. This group also included one of the authors of this publication. First of all, the group began to clarify the range of problems related to the philosophy of education. This was a new matter, and from the very beginning it was necessary to solve not only and not so much practical problems as to identify and substantiate the conceptual contours of the philosophy of education itself, its categorical apparatus. Since then, about a quarter of a century has passed, so we can compare what we started with what it has come to at the present time.

M. Scheler wrote that "so far no one has tried to give a philosophical, essential definition of education," that anyone who seeks to get an education or give it to others must understand three circles of problems: "First, what is the essence of "education" at all? Second, how does the education process take place? And, thirdly, what types and forms of knowledge and cognition condition and determine the process by which a person becomes an educated being? " [4]. 
In fact, a program for the development of the philosophy of education is formulated here. At the same time, the first circle of problems involves the need to study the idea (meaning) of education. It also contains the main question of the philosophy of education.

\section{Materials and methods}

This article is based on the materials of a small sociological study of practical workers in education, analysis of materials devoted to the development of programs for the development of education in different regions of Russia in the 90s. The methods of system analysis of the phenomenon of education are used: logical and historical, structuralfunctional, whole-private relations.

\section{Results}

Thinkers have been thinking about the essence of education for a long time. It was noted that the problem of education is exacerbated during the crisis periods of the existence of society, when the question arises before it: where and how to go next? On the surface of public life, this issue usually splits into a host of questions about economic and political reform, about the reorientation of ideals and moral values. All of them are extremely important, and the fate of society depends on their decision. But these are external, secondary questions, behind which something deep and fundamental is hidden.

To reorganize the economy, you need to understand where and at what time you should make maximum efforts, and which steps lead to a dead end. To reorganize the political system, one must have an idea of the peculiarities of the state organism and clearly understand what will take root on it and what is contraindicated for it. To engage in the transformation of moral values, one must first identify and feel the depth of the people's memory, analyze the shifts that naturally occur in the depths of the spiritual life of the people, once again determining what "works" for the rooting of values, and what hinders their implementation.

All this rests on knowledge, understanding, comprehension of life, although it is not limited only to them. All of this is covered in one word - education. There is not a single sphere of life, wherever it penetrates. Of course, in politics, economics, ideology, you can act on a whim, without any education. I. A. Ilyin noted on this score that "many semieducated and amateurs irresponsibly engage in irresponsible politics. People put the wrong questions, solve them at random, write, print and phrase ... phrase words endlessly "[5]. As if written off from our reality! But are not phrase-mongering and inspiration the simplest, most primitive stages of education, the essence of which is that a person learns to see only to the tip of his nose, no further?

As an axiom, let us designate the following provision: education is at the heart of various social deeds. Then it is clear why the problem of education is actualized during periods of crisis. In essence, the crisis encompasses the end of the previous development and the beginning of the next stage. It means the end, since the possibilities laid down in the previous period either realized, exhausted themselves, or did not open at all, so that there is a need to identify new possibilities. It means the beginning, since every movement begins with the identification and implementation of possibilities, and this requires energy, will, means, perspective. Otherwise, as through education, it is hardly possible to acquire all this. It is no accident that M. Scheler said that "when, in a difficult struggle for a new world, a new person dares to create new forms, the problem of human education becomes central" $[6,20]$. I.A. Ilyin, who pondered a lot about the ways of development of Russia, 
emphasized that its fate "lies in the hands of a Russian teacher - a school teacher, as well as a professor who is a teacher of teachers" [7].

Education is a process actually carried out in a particular society, where a huge mass of practical workers are employed. How do they imagine education?

In the Pskov Regional Institute for Advanced Training of Educators in the mid-90s, one of the authors of these lines suggested that educators at various seminars and courses answer M. Scheler's questions (see above). A total of 87 people gave answers. They reduced the essence of education mainly to the acquisition of knowledge, abilities and skills, the education process was presented in the form of preschool, school, university and postgraduate levels, while emphasizing that it is necessary to engage in continuous selfeducation.

We can say that the answers in general were characteristic of the pedagogical paradigm that dominated the system of pedagogical education in the Soviet period. Such answers are also characteristic of everyday consciousness, which usually follows the established practice of obtaining education. But they cannot give an impetus to thinking about education as a fundamental problem for a person and society.

If education is limited only to the acquisition of knowledge, skills and abilities, then it should intuitively be presented as something secondary in a person's life. Many disciplines that are studied in school turn out to be unnecessary in later life, unless you devote your life to the study of any science. Hence the "deep" idea is born to teach at school only those subjects that are important for life. However, hardly anyone will take the liberty of compiling a complete register of those subjects that are important to life and that should be studied in school in order to prepare a person for practical life. There is a very large proportion of the fact that among such items, the so-called pragmatically useful items (gardening, housekeeping, rabbit breeding, etc.) will become established, which, however, have a very distant relationship to the universal development of man.

The number of subjects in the school is growing, the flows of information that the student must pass through him are increasing. It is impossible to know everything, but what you know is forgotten over time, becomes obsolete. The wise Heraclitus argued that knowledge of the mind does not teach. Therefore, education is essentially not related to the amount of information received. Knowledge as information about the world is an important, necessary component of education, but by no means an exhaustive education. Education is not knowledge about the world, it is not the sum of knowledge, although without knowledge one cannot speak of education.

It is unacceptable to reduce education to the acquisition of skills and abilities. The ability to cook deliciously, the skill of driving a car is certainly highly valued by people. But you can't call a person educated who skillfully cooks or sews boots - that's all. Even a shoemaker who does his own business, in one way or another, seeks to go beyond the narrow framework of his craft and compensates for the narrowness of this occupation by the desire to reason on general and abstract topics and often expresses rather deep thoughts. "A Russian illiterate peasant," N. A. Berdyaev wrote about this, "likes to pose questions of a philosophical nature - about the meaning of life, about God, about eternal life, about evil and untruth, about how to realize the Kingdom of God" [8] ... But this inclination to philosophizing testifies, rather, precisely to the need to overcome skills and abilities, to the striving for wisdom, rather than to cultivate a certain kind of occupation and give it the character of universality. Thus, education itself, in essence, is the desire to go beyond the narrow framework of a particular occupation and gain a broad vision of the situation.

Here's another impressive example. I.A. Ilyin tells about one incident from his life. Once a neighbor came to him - to talk, to relieve his soul. And at the end he told about his father, a tailor. This tailor was a wise man and made generalizations truly universal. He 
compared people to a cloth: in it, each thread was woven with another, they all supported each other. If one thread was torn, then a piece of fabric turned out to be defective. This is, so to speak, an empirical observation taken from a sphere close to the tailor. But from this observation, through analogy, he passed on to people: this is how it is with them, we are all one continuous fabric, we all stick to each other. "If one feels bad, then everyone feels bad, but people do not understand this: they are stupid, short-sighted. As in the farm. A poor man is not poor for himself alone, but for everyone. A beggar does not ask for himself, but worries others ... Where there is trouble, there is common trouble. And again, the entire fabric is damaged, it is necessary to repair it as soon as possible ... We are all threads in the fabric of God ...".

This means that limiting education to the acquisition of knowledge, abilities, skills means deliberately hindering the development of a person's capabilities and abilities and putting him in such conditions that he degrades. In terms of its volume and content, education is many times greater than knowledge, abilities, and skills. It is appropriate to make such a comparison: to limit education to knowledge, skills and abilities is the same as reducing the rich world of trees to alder, pine and palm, excluding all other species from the sphere of attention. Knowledge, skills and abilities are only part of education.

Among the other answers to the questionnaire, the following can be cited: a) education is the improvement of a person's mental abilities, b) adaptation in the world. But even they cannot be attributed to the most important signs of education.

The improvement of mental abilities fits the new European paradigm of rationalism and suffers from an orientation towards the development of only the mind, while the spiritual and mental world of a person in this case falls out of the sphere of education. Ignoring the spiritual, moral and emotional development of a person dooms to failure any model of education, no matter how sophisticated it may be in improving mental abilities.

As for the adaptation of a person in the world, the philistine principle "my house is on the edge" is a vivid expression of such adaptation, but one should not put it at the head of the educational process. The essence of this principle is isolation from the world, focusing exclusively on one's own interest, while education opens the world to a person, leads him to where he needs to be able to both adapt and orient himself. But adaptation is just one of the moments in the structure of education, which cannot be the goal of education.

Education is not limited to mastering information, although without information it is impossible to build either tactics or strategy of activity. Education is not limited to knowledge, although knowledge is one of the conditions for education. Education is neither upbringing, nor introduction to culture, nor the formation of morality. If education were reduced to at least one of these components, then one of these concepts would be superfluous (if education is upbringing, then it would be necessary to talk only about upbringing, and "education" would become an unnecessary concept). If education, for example, is defined through morality, then the question of the essence of morality would arise, and this is already a new independent problem. As a result, we would reduce one unknown (education) to another (morality), which would by no means bring us closer to understanding the essence of education.

From what has been said, it is already intuitively possible to grasp that education includes many different components, but is not reduced to any of them, either individually or to their sum. It is something whole, a single one, which is precisely reflected in the idea of integral education precisely as an education, and not in its separate, often accidentally snatched, components. As a whole, education is "inscribed" in the real life of a person and society; it is itself an extremely complex phenomenon of the social process that allows for various interpretations. The foregoing speaks of the need to develop such a definition of 
education, in which there would be no indication of its individual components. Searches for such a definition in the literature are found one way or another. Here are some examples.

D.V. Pivovarov writes: "Education is immersion in the ideals of a particular culture. The general education system in society is aimed at mastering the most valuable sacred and secular ideals by the individual ". We find a different approach in O.V. Dolzhenko, who asserts that education is a "function of life". Sometimes education is viewed in the historical and evolutionary aspect, as an evolutionary mechanism. These and other statements indicate that in modern Russian philosophy, pedagogy and psychology, a more fundamental understanding of education is "maturing" than that which connected it only with the acquisition of knowledge, skills and abilities.

Note that classical philosophy has always required a fundamental approach to education. Hegel wrote that a person is, firstly, a separate person (individual), secondly, he belongs to a natural whole - the family, thirdly, he is a member of the state, and fourthly, enters into relations with other people. As an individual, he refers to himself, he has two sides - singularity and universal essence. Proceeding from this, Hegel sees the task of education in the fact that man should raise "his separate being to his universal nature," and this means to form himself. The essence of education is, according to Hegel, in the ascent of man from his singularity to universal nature. In this regard, Hegel examines the tasks of theoretical and practical education, and he presents the ascent of man to universal nature as a process of deepening man into the essential, as a limitation of natural needs in favor of higher duties, which he associates with the mastery of man's spiritual forces in order to fulfill his higher purpose.

Hegel is echoed by the prominent modern representative of hermeneutics H.-G. Gadamer, who asserts that education "as an ascent to the universal is thus the task of man". And he writes that education is not a question of experience or life, but a question of the past formation of being. Thus, to characterize education, two fundamental categories "becoming" and "being" are involved, correlated, moreover, with each other in a single formula "becoming of being".

Many philosophers, not without reason, believe that the most fundamental, basic category for understanding the world is the category of being. It expresses what is inherent in all phenomena, events, things without exception: before they are a certain thing, a certain event or a phenomenon, they must simply be. Being is a necessary precondition for any conversation about objects and processes. It is expressed by the well-known word "is". Being as simply "is" is opposed by non-being as "not is". One assumes the other, one manifests itself against the background of the other. Noting this circumstance, let us emphasize that being and non-being not only exclude each other (being is not non-being and vice versa), but also mate with each other, forming a single link "being-non-being". It also represents becoming as an inseparable unity (and even identity) of being and nonbeing. Therefore, "the formation of being" means that in the world in the process of continuous interaction of being and non-being, that is, in becoming, certain forms of being, things, objects, phenomena are affirmed, which are fixed by us as existing, as a huge variety of existing.

The process of education ontologically is the emergence, confirmation and consolidation of different forms of being. As applied to a person, this means that in the process of education, a person comes to new forms of his being, and he changes a) the conditions of his existence, b) his attitude towards other individuals, c) his way of life, d) means his life itself. But what does "change your life" mean? In this context, what is the purpose of a person, the meaning of his life?

It is precisely Hegel who answers these questions, whose words we quoted above. Gadamer continues Hegel's line of reasoning: "The general essence of human education is 
that a person makes himself in all respects a spiritual being. Anyone who surrenders to particulars is uneducated ". In other words, to ascend to your universal nature means to make yourself a spiritual being, that is, to become just a Human, to achieve your highest destination. It is clear that this cannot be achieved by knowledge, skills and abilities alone. Here, as they say, it is necessary to resolutely change the entire human nature: body, soul and spirit.

Unfortunately, the policy of modern Russia in the field of education is directed exactly in the opposite direction. Yu. V. Gromyko generally gives an impartial characterization of modern education: "Today Russian education is a disabled person. Nowadays it is a dying creature, strangled by foreign elements: the Bologna system with an endless bureaucratic rating of students according to the "necessary" form; debilizing exam; thieves' principle "money follows the student." And most importantly - the Federal Law "On Education in the Russian Federation" dated December 29, 2012 No. 273-F3, which declared education a service, and not a common good ". And he states that in Moscow education "a society is emerging from three divided groups - a narrow stratum of students from super-expensive elite schools, such as the Gref school or the Pavlovsk gymnasium, where children are brought on Rolls-Royces and helicopters, a layer of individually successful ) and a huge part of the "cut off". Instead of teaching, educating and promoting everyone, the most expensive Moscow education divides and selects".

Education is ontological; it is, according to M. Scheler, a category of being. It is this circumstance that allows us to speak about its fundamental role in human life. And when philosophy raises the question of a person's place in the world, then one cannot do without the category of education, because in an extremely broad interpretation, education is the placement (assertion) by a person of himself in the world through transformation of himself and the world, as a result of which a person merges with the world, the world acquires a human dimension, and man acquires a universal meaning as a rational-spiritual being through whom the world goes to itself. Education is precisely the process of meeting a person and the world. That is why education is an attribute of a person's being, precisely because it accompanies him all his life.

\section{Discussion}

Approaches to clarifying the essence of education can and should be - based on the variety of tasks and goals - different. However, sooner or later, thinkers engaged in this area will have to "rest" on the question of the foundations of the foundations of education. They will face the full growth of the problem of identifying those first principles on which the educational process is based. The road to these first principles is not easy. He does not tolerate haste and does not promise immediate practical results. But it is necessary to pass this path in order to understand the essence of education. And only after clarifying the first principles, you can safely go back, plunge into the empiric of education, where these very first principles function spontaneously. Then you can see exactly how they function, intervene in the educational process and direct it in a certain direction.

Plato made a remarkable discovery in his time. He found that every thing has a certain idea. More precisely, the idea encompasses a class of homogeneous things. For example, the real thing - the table - has its own idea of the table. Moreover, it is one for many real tables and can be embodied in its various carriers-tables. Tables are made of wood, metal, plastic, round, square, sliding, folding, etc. But they are all united by one common idea of the table. But why do things need an inherent idea? Isn't it easier to think that there are only things without any ideas? 
Let us assume that there are things that have no corresponding ideas. Let's say for the sake of simplicity that there are only two such things: a table and a chair, for example. Are these things different from each other? If they do not differ, then we cannot indicate in this case where is the table and where is the chair. Moreover, since they are no different, we cannot even say how many things are in front of us - two or one, because they are no different, according to our assumption. If no two things differ from each other in any way, then we will not be able to distinguish them from many things, because in addition to two things, there are many others. But we will not even be able to point to any multitude of things - after all, they will all merge into one indistinguishable haze. Common sense tells us that one thing is different from another, that a table is not a chair, and vice versa, a chair is not a table. So things are different from each other. What exactly?

Things differ from each other in their properties, their purpose. The table, for example, is wooden, and next to it is a plastic chair. In addition, the table is white and the chair is black. Properties belong to the things themselves and characterize things in a certain aspect. We distinguish things from each other by fixing the difference in their properties, shapes, sizes, establishing the presence of some specific combination of properties, etc. But since a thing has certain properties, then it itself is something definite, which is precisely this thing, and no other. By fixing the totality of table properties, we express the idea of the table; establishing the set of properties of a thing, we come to the idea of a thing. The idea of a thing "is something essential, vital and reasonably necessary for us to know this thing ...". Every thing, everything that exists in the world has its own idea. An idea contains the meaning of a thing, while a thing becomes meaningful only when its idea is revealed. That is why the idea of a thing is absolutely necessary for the existence of the thing itself. If a thing has no idea, no meaning, then this means that it is a meaningless thing that does not manifest itself in any way and anywhere, because that which is different from the other is manifested, and to be different just means "to have an idea (meaning)". The idea of a thing just answers the question: what a given thing is.

Why are we starting this conversation about a thing and its idea? Moreover, education is also a kind of "thing", therefore, it has its own idea, its own meaning. And in order to understand what it essentially represents, it is still necessary to "get to the bottom" of its idea.

So, there is education in itself, as a real process (real thing), and education in its idea (as the meaning of a real thing). What conclusions follow from this circumstance? One of them is that it is impossible to tear one away from the other. The second is that mixing them is also impermissible, because this creates the illusion that everything that happens to a thing, in our case to education, is immediately given as the meaning of a thing, that is, education. The third requires special comments. It lies in the fact that very often in practical life, reflecting on the essence of education, you hear: all this has nothing to do with reality, leave your high matters and move on to life, study what is being done in a particular school, the functions of a school principal, head of education department, etc. In a word, stop thinking, plunge into the real thing, be a pragmatist. And we usually like to boast of their pragmatism, completely unaware of the consequences arising from the subject of such pride and arrogance. The call to be closer to life, for all its impressionability, actually orients us towards breaking the idea of a thing and the thing itself. The idea of a thing is "the semantic and essential side of a thing, indicating ... its purpose". And if we follow this call, then in fact we are closing the way to the study of the meaning of education.

The idea of a thing is not only necessary for the existence of the thing itself, but also differs from it, from the material of the thing, in its insubstantiality. The idea of education points to the real process of education, but itself remains immaterial, purely semantic, allowing one to rise above the element of education and look at the educational process as 
if from the outside, to survey it as a whole. Unfortunately, it is poorly understood by practitioners from education. It is also regrettable that the position of disregard for the idea (meaning) of education is cultivated by a number of sciences dealing with education.

Pedagogy, economics of education, sociology of education, management in the field of education - all of these, as well as many other sciences, sometimes deceive themselves by the fact that they are studying various aspects of the real educational process, ignoring the special formulation of the question of the meaning of education. This could not have been mentioned, if not for one curious circumstance. It turns out that you can talk and write about education without knowing what education itself is.

However, this should not be surprising. Before us is not an exception, but a fairly typical phenomenon. It is well known that a child can be taught to perform arithmetic operations, and he will successfully add, subtract, multiply, divide, in a word, handle numbers without having any idea what a number is. We successfully drive a car, turn on the TV without looking either under the hood or behind the back wall of the TV - this is not what we need. Having got sick, we take the medicine prescribed by the doctor, not being interested in its chemical composition, without thinking about the physiological mechanisms of action of the tablets. Yes, and living life, can we say for sure what life is? What is love? And for the time being, these questions do not arise at all. So it is with education.

You can write textbooks, develop teaching technologies, give lessons, hold teachers' councils, give lectures and ... have no idea at all about the essence of education. The process goes by itself - very good! But the question of the meaning of education sooner or later arises. And it arises precisely because, on the one hand, there is the element of education, and on the other, the need to give this element a definite form, to structure it. But the question itself is possible insofar as it presupposes the existence of the idea (meaning) of education. There is no point - there is nothing to ask.

Sooner or later, the question about the meaning of education arises in the following form: how much does the real educational process correspond to its idea? Or, in other words, to what extent has the idea of education been realized in reality? Sometimes it rises in an affirmative form, when our "wise ideologists and politicians from education" suddenly wake up and begin to actively scream about some kind of challenges that modernity throws at the supposedly lagging education. But as soon as this question appears in the practice of education, the main question inevitably arises: what is education in general? What is its meaning? What should be the idea of education?

This is the question of questions - the question of the idea of education, which is the main question of the philosophy of education.

Having formulated it, we left the realm of real education to reflect on the essence of education. After these reflections, only the perspective is revealed. To have a clear concept of education means to explicate its meaning precisely as education, answering the question: what is education in its last being?

As soon as we turn to the idea of education, as soon as we find that the idea of a thing is not at all reduced to the material basis of the thing itself, to the totality of its material properties, it immediately becomes clear that only the material and technical equipment of educational institutions, for example, computerization and the following total digitalization of the educational process does not exhaust the idea of education and does not even bring it closer to its implementation.

The idea of a thing is something immaterial, immaterial. This is also true of the idea of education. It is important to talk about the latter, since the presence of the idea of a thing is the most important condition for knowing the thing itself. There is no idea of education there is nothing to cognize and relative real education. But as soon as there is an idea of 
education, then its presence allows you to streamline the chaotic mass of signs of the educational process, to bring them together.

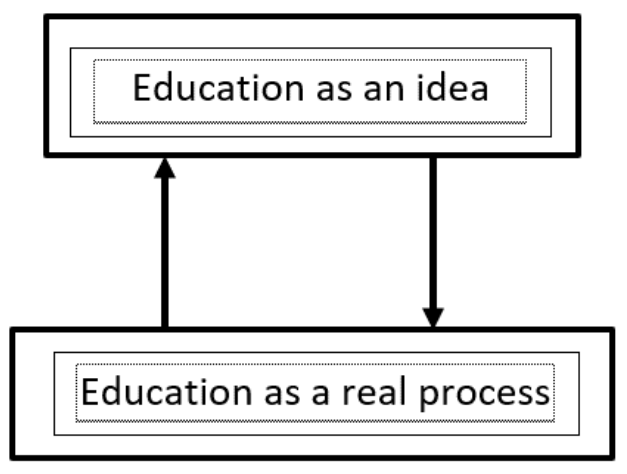

Fig. 1. The main question of the philosophy of education is the question of the correspondence of the real process of education to the idea of education.

The idea of education requires that we approach the study of education as a kind of wholeness that brings together the diverse manifestations of education, its different types and levels into a certain community governed by a general law that sets all kinds of its changes and functioning. Finally, since the idea of a thing is the ultimate generalization of a thing, there is its "limit, infinite for all final states and manifestations of any single thing bearing this idea", insofar as the idea of education is in strict accordance with what has been said is the ultimate generalization of all educational processes and their final manifestations in a particular area, in a particular region. And in this sense, it serves as a starting point for the analysis of many single states of education, which the pragmatic practitioner who is numb before the pressure of meaning is so afraid to lose sight of. That is why a philosophical study of education is necessary, which consists in revealing the meaning of this extremely diverse and complex phenomenon.

The idea of education brings together various signs of the formation of the process, gives it integrity and wholeness, representing a new quality of education in relation to all its individual signs. This wholeness is irreducible to nothing else; it is it that expresses the essence of education as such.

The first thing that can be said about education in this regard is as follows. The idea of education clearly indicates that education should be approached as a whole, absorbing everything related to education. The idea of education makes it possible to formulate the principles of a holistic vision (consideration) of education. As long as and insofar as education as a whole includes all its characteristics and properties, it represents in this respect "everything that exists in education itself," that is, it is a universe. Only the whole is capable of being a universe. The universe is not only and not just a whole, but includes many parts.

Therefore, further, it can be argued that education as a universe (as a whole) can be "decomposed" into component parts (parameters), each of which has specificity, is different from all others, and all together they define and, possibly, exhaust it, thus ensuring the completeness of the consideration of the universe of education, bearing on itself its meaning precisely as a whole.

The foregoing suggests a methodology of whole-part relations, which can be applied in the analysis of education. The essence of this methodology, in short, is as follows. 
Education as a process actually carried out is a kind of indivisible singularity, which is expressed in the fact that it has its own idea - this is precisely the idea of education. Education is precisely education, not the economy, not space flights, not the government. It is a whole. At the same time, it consists of different parts. For example, there is secondary and higher professional education, it can be full-time and part-time, and so on. And there are quite a few such parts. Education is a unitary structure. It is united because all parts of it are included in education. Separate - since there are quite a few of these parts, they do not overlap and are described using the category "part".

Part and whole are correlative categories. One does not exist without the other. If we are talking about the whole, then we think first of all as an indivisible singularity, consisting of many parts. If we are talking about a part, then we mean the presence of a certain whole, in which the parts are isolated. There is no whole without parts. The part outside the whole is no longer any part. With regard to education, this means that when we talk about it as a whole, we must also indicate its parts; when it is spoken about parts of the educational process, then the criterion for distinguishing them and attributing them to education should be that the part bears the meaning of the whole, i.e. education as a universe.

Part and whole are not only correlative, but also opposite: the whole is not a part, a part is not a whole. This allows you to highlight exactly the parts and consider them yourself. It should be borne in mind that in the composition of the whole there are different parts, which have their own purpose. But they interact with each other, otherwise the whole cannot arise. It is the whole that gives unity and even identity to its parts, since it is an indivisible singularity that pulls together all its parts.

Restricting ourselves to these moments of the dialectic of whole-part relations, in addition to what has been said, we will quote the words of N.O. Lossky, which seem to us extremely important: "1) each part exists for the whole, 2) the whole exists for each part, and 3) each part is a whole in some special aspect of it ". The first two provisions speak about the originality of the interaction of the part with the whole, while the third proclaims the possibility and legitimacy of considering the part as a whole. This means that in the universe of education, it is possible to distinguish different parts that make sense precisely in the context of education as a whole. According to the third position, each part can be "enlarged" to a whole, in which, again, different parts can be highlighted. Thus, we can talk about the presence of different systems in the structure of education. But this position can be turned around and talk about the universe of education as a part of a larger whole. Thus, when studying education, it is legitimate to single out the internal and external contexts of education itself, the relationship between which can turn out to be arbitrarily complex.

So, education as a universe is a whole that has its own internal structure, which is inscribed in a larger whole, and therefore is a part of this new universe.

Education as a whole has an internal context where its own meaning is set. It is education as a whole that corresponds to its own idea, which makes education an education and nothing else.

Education as a part is part of a larger whole, another universe, which, for example, is society. As a part, it bears on itself the meaning of the social whole, reflects the change in the historical types of society. At the same time, a person as a generic being turns out to be a broader whole in relation to education. In this capacity, man and society are not only comparable, but commensurate universes overlapping each other, so that the meanings of education in this conjugated context of theirs form something new.

Therefore, the own idea of education, taking into account these occurrences, presupposes the analysis of the individual, the state, and society in their relation to education. At the intersection of all these relations, a system of contradictions is tied, which has to be considered both theoretically and practically, preserving and developing the 
existing education system. Thus, the semantic sphere of the analysis of education is outlined, a kind of semantic quadrangle, which has as its peaks the state, society, man and education.

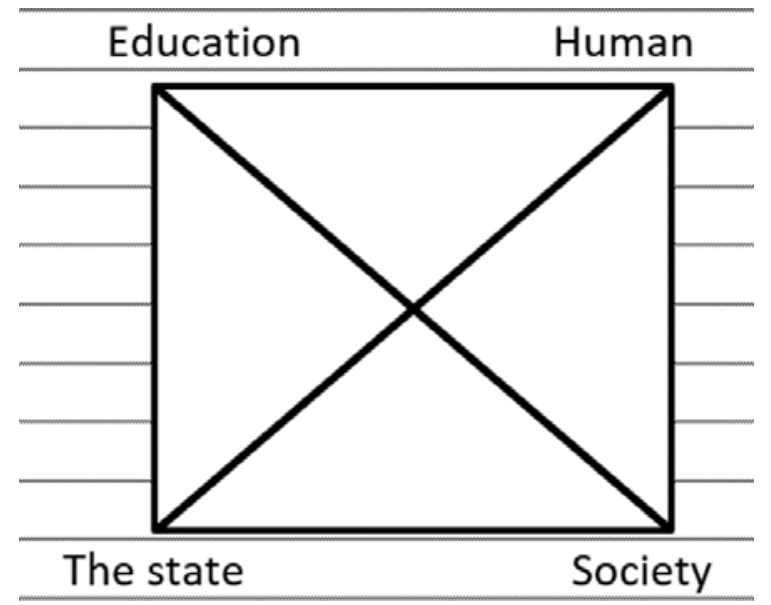

Fig. 2. Semantic square of education: multifactorial interactions.

The complexity of the philosophical analysis of education lies in the fact that, taking into account this quadrangle, it should be clearly understood that each of these peaks is not just connected with the other two, but is revealed through the others.

\section{Conclusion}

Discussion of the problem of education as a universe shows that in modern research on the philosophy of education there is a lowering of the status of this branch of philosophical knowledge as universal knowledge to the level of special sciences. As a result, the efficiency and effectiveness of predictive conclusions regarding the future state of education in society decreases.

The Russian philosopher S. I. Gessen considers pedagogy as applied philosophy. This is fully justified, because it expands the instrumental capabilities of philosophy and elevates pedagogy, since a solid worldview and methodological foundation is put under it.

Modern researchers of the philosophy of education, on the contrary, often lower the status of this discipline, understanding it rather limitedly from the point of view of philosophy itself, and very smoothly and imperceptibly for themselves move into the sphere of a completely different venerable, but private science - pedagogy.

The generic characteristics (parameters) of philosophy are: the doctrine of a) about the universal, b) about the origins and c) about the passage to the limit. And in the specific discipline "philosophy of education" they must be fully preserved. Otherwise, the status of philosophy in the philosophy of education will sooner or later be lost.

The philosophy of education in accordance with point a) is the doctrine of the universality of education for a person, society and, we will not be afraid of this word, for the world as a whole. In accordance with point b), the philosophy of education is the doctrine of the origins of the educational process, therefore, it must deal with the clarification of where education begins, what lies at its origins, and this is a question of the metaphysics of education. Finally, in accordance with point c), the philosophy of education 
should clarify what education is and what it is not. This is the question of the boundaries of education, its passage to the limit, which must be explicitly designated.

Currently, there is a substitution of the philosophy of education by pedagogy and even the history of pedagogy, which can be found in a number of work programs on the philosophy of education posted on the Internet. In many publications, the philosophical understanding of the educational process is blurred, and sometimes the authors move from a cursory characterization of the philosophy of education to an exposition of the historical and philosophical ideas about education, which they find in the teachings of philosophers of the past, and to a discussion of the ideas of didactics and education in a pedagogical direction [25]. But this path of development of the philosophy of education, we repeat, means the erosion of the subject of the philosophy of education and significantly limits its possibilities in the matter of ideological and methodological analysis of the educational process.

\section{References}

1. O.A. Beregovaya, Philosophy of Education in Modern Russia. Vestnik Severnogo (Arkticheskogo) federal'nogo universiteta. Sen: Gumanitarnye i sotsial'nye nauki, 3, 31-39 (2017) DOI: 10.17238/issn2227-6564.2017.3.31

2. A.P. Ogurtsov, V.V. Platonov, Images of education: Western philosophy of education. XX century (Saint Petersburg: RHGI, 2004)

3. E.V. Bryzgalina, A.R. Kurbanov, E.K. Sungatulina, Bulletin of Moscow University, 7, 1, 41-60 (2012)

4. I.A. Ilyin, Singing heart. The book of quiet contemplation. Op. in ten volumes. T.3. (M .: Russian book, 1994)

5. D.V. Pivovarov, Philosophy of religion (M.: Academic Project; Yekaterinburg: Business Book, 2006)

6. O.V. Dolzhenko, Essays on the philosophy of education (Moscow: 1995)

7. Yu.V. Gromyko, Russian education system today: a decisive factor of development or a path to the abyss? Education as a political technology (M.: LENAND, 2019) 